\title{
A "INCLUSÃO" DE HOMOAFETIVOS NA EMERGÊNCIA DO NOVO CAPITALISMO: ANÚNCIOS PUBLICITÁRIOS E OS NOVOS ESTUDOS DE LETRAMENTO NA ESCOLA REFLEXIVA.
}

\section{THE "INCLUSION" OF HOMOAFETIVES IN THE EMERGENCY OF THE NEW CAPITALISM: ADVERTISING ANNOUNCEMENTS AND THE NEW STUDIES OF LETRAMENTO IN THE REFLECTIVE SCHOOL.}

Humberto Silva de Lima ${ }^{1}$

\section{RESUMO}

Tendo como base a perspectiva da "virada cultural", os novos estudos de letramento têm motivado movimentos convergentes para a desconstrução da ideia de que certos estados de coisas são considerados "normais", enquanto outros são "desviantes" ou "marginais", no que tange às práticas de letramento e sua produção e recepção. Nesse âmbito, o objetivo deste artigo é, por meio da Análise Crítica do Discurso, proposta por Norman Fairclough (2001), discutir como a voz dos homoafetivos pode ser legitimada na multissemioticidade do gênero discursivo anúncio publicitário, ainda que essa legitimação seja posta em relevo pelos interesses do novo capitalismo na era pósmoderna.

PALAVRAS-CHAVE: homoafetividade; análise do discurso; novo capitalismo; discurso publicitário.

\begin{abstract}
Based on the "cultural turnaround" perspective, new literacy studies have motivated convergent movements for the deconstruction of the idea that certain states of affairs are considered "normal", while others are "deviant" or "marginal" in the practice of literacy and its production and reception. In this context, the objective of this article is, through the analysis of the critical discourse, proposed by Norman Fairclough (2001), to discuss how the voice of the homosexual relationship can be legitimized in the multisemioticity of the discursive publicity genre, although this legitimation is put in relief by the interests of the new capitalism in the postmodern era.
\end{abstract}

KEYWORDS: homosexual relationship; discourse analysis; new capitalism; advertising discourse.

\section{INTRODUÇÃO}

A partir da segunda metade da década de 80 do século passado, o campo da educação e o das ciências linguísticas assistiram a uma significativa mudança quanto à distinção entre as práticas de alfabetização e as de letramento. No Brasil, é na obra No mundo da escrita: uma perspectiva psicolinguística, de Mary Kato (1986), que se tem o primeiro registro do termo "letramento", referente à necessidade de a escola inserir a criança no mundo da escrita, tornando-a capaz de se desenvolver

\footnotetext{
1 Doutorando em Linguística Aplicada Interdisciplinar pela Faculdade de Letras da Universidade Federal do Rio de Janeiro (UFRJ). Rio de Janeiro - RJ, Brasil, humbertotalk@gmail.com.
} 
cognitivamente, satisfazer as suas necessidades e atender às demandas sociais diversas que veem a escrita como um poderoso e hegemônico instrumento de comunicação.

Essa acepção foi posteriormente ampliada com reconhecimento de diversas condicionantes no processo de alfabetização, sejam elas de cunho sociolinguístico, cultural e político, no sentido de entender que o letramento não era sinônimo de alfabetização, reconhecendo-se a possibilidade de alguém ser letrado mesmo que não tenha sido alfabetizado. Exemplo disso é que um analfabeto, quando ouve no rádio que o preço do botijão de gás irá aumentar na semana seguinte, no dia posterior da audição do programa radiofônico, vai ao posto mais próximo e compra o produto pelo preço ainda não reajustado. $\mathrm{O}$ analfabeto que comprou o botijão de gás ouviu um texto oralizado, isto é, um texto escrito, inserido no gênero discursivo notícia, lido pelo locutor da estação de rádio; ao compreender o conteúdo da notícia, ele entendeu a necessidade de apressar-se com a compra do botijão, caso não quisesse pagar mais caro pela mercadoria. A aquisição foi possível, em termos da prática e da recepção de letramento, por causa da escrita da notícia pelo repórter e da leitura do texto pelo locutor (a prática), bem como do entendimento do ouvinte quanto ao conteúdo da notícia transmitida (a recepção). Nesse âmbito, como a relação entre ser letrado e ser alfabetizado não é linear, Soares (1998) e Tfouni (2010) defendem a ideia de níveis de letramento em prol da compreensão e expressão de significados. Assim, o processo de letramento se insere em um continuum, haja vista que não existe, nas sociedades industrializadas, letramento de grau zero.

Entretanto, outras perspectivas teóricas surgiram e ultrapassaram as visões de letramento ser sinônimo de alfabetização ou mesmo se circunscrever à ideia de continuum. É verdade que os estudos anteriores já enfatizavam a ideia de a leitura e a escrita serem práticas inseridas em contextos socioculturais específicos (SOARES, 1998), mas não no sentido mais abrangente dos New Literacy Studies, que, segundo Gee (2000) e Street (2003), se reportam à chamada "virada cultural" nos estudos de letramento. Para esses autores, a abordagem crítica dos novos estudos de letramento apresenta vários movimentos convergentes para a desconstrução da ideia de que certos estados de coisas são considerados "normais", enquanto outros são "desviantes" ou "marginais", no que tange à produção e recepção de diversas práticas de letramento, e essa "virada" vai de encontro à postura behaviorista ou mesmo à perspectiva do conhecimento cognitivo. Assim, quebram-se paradigmas tradicionais de leitura e produção de textos, agregando-se aos estudos de letramento a visão do caráter da multissemioticidade discursiva. Entra em cena o que Rojo (2012) chama de pedagogia dos multiletramentos, que vai além dos letramentos múltiplos por incorporar a multiplicidade de linguagens e culturas desessencializadas e transgressoras de relações de poder estabelecidas.

Nessa perspectiva transgressora, motivam-se várias discussões sobre a importância da diversidade cultural e de linguagens, a começar na escola, visto que novas formas de comunicação e informação têm reconfigurado as práticas sociais da leitura e da escrita e sua aprendizagem (ROJO, 2012). É nessa reconfiguração que se vislumbra a importância da multimodalidade ou multissemioticidade dos textos, cuja abordagem enfatiza que não é só o código escrito que tem relevo na composição do sentido do texto, mas também as cores das letras, a disposição da imagem utilizada e outros elementos não-verbais, que concorrem para a composição de um todo significativo (KRESS, 1997; ROJO, 2012).

Observa-se daí então uma nova ética, em que não se promove a cultura do "vale tudo", do relativismo acrítico, mas a de que todas as normas e valores são iguais, todas as formas de pensar, no mundo global, são válidas, procurando-se, por meio de uma análise crítica, excluir, no campo social, determinadas formas significativas que promovem sofrimentos a determinados grupos (MOITA LOPES, 2006). A produção de textos multissemióticos, segundo práticas discursivas específicas, têm explicitado a inserção de vozes até então excluídas na produção discursiva de significados. Todas as vozes têm relevância e precisam ser legitimadas, a começar na aprendizagem das práticas de 
letramento no contexto educacional, a fim de que se construa uma escola reflexiva, que pode não só avaliar seus projetos educativos, mas também produzir conhecimentos sobre si mesma, inserida numa sociedade que precisa, em todo o tempo, rever os próprios conceitos, de modo que determinados grupos, antes excluídos, tenham voz e reconhecimento. Trata-se do compromisso da escola na construção de uma sociedade de fato justa e democrática. Isso será possível se aceitarmos a ideia de a escola ser não somente globalizada, mas sim "glocalizada", o que explicarei mais adiante.

Diante dessas questões preliminares, proponho neste artigo, em diálogo com o que se pensa a respeito dos novos estudos de letramento, uma breve reflexão sobre como essas vozes antes excluídas podem ser legitimadas na multissemioticidade do gênero discursivo anúncio publicitário. Parto do princípio de que, no contexto do pós-modernismo, a fluidez, o hibridismo e a produção hipertensa do novo capitalismo têm direcionado a prática discursiva dos anúncios a identidades específicas de consumidores, dando-lhes legitimidade e reconhecimento no que tange ao consumo de produtos que, até então, eram destinados apenas a um determinado tipo de grupo. Tomando a proposta de Análise Crítica do Discurso (FAIRCLOUGH, 2001), apresento dois anúncios publicitários, cujas marcas, Leite de Rosas e O Boticário, voltadas para a venda de artigos para o toucador e de perfumes, vêm legitimando, em nível do discurso, o grupo dos homossexuais como consumidores em potencial - isso não significa que esse grupo antes assim não fosse, mas que agora a propaganda o insere como consumidor, desconstruindo-se assim o preconceito de que os homossexuais não desfrutam dos mesmos direitos dos heterossexuais. Todavia, procuro defender que, em meio a essa ideia de inclusão, pela agenda voltada para os direitos dos homoafetivos, amplamente discutida hodiernamente, o novo capitalismo, com sua força híbrida e polivalente de atuação, tem incorporado tal agenda. Se por um lado a marca acolhe o homoafetivo como aquele que pode construir uma família, fato esse criticado erroneamente pelo heteronormativismo, esse acolhimento, que é, de certa forma, benéfico, não passa de uma reprodução de um dos anseios do sistema capital: inserir discursivamente novos consumidores (no caso, os homoafetivos) para chamar a atenção do produto por meio de uma ideologia polêmica, na busca desmedida do aumento de vendas e do consequente lucro. Tal análise deve fazer parte do que se entende pela prática consciente do letramento, a qual deve começar na escola, em prol de uma educação reflexiva.

\section{A escola reflexiva "glocalizada" no novo capitalismo}

Apple (2000) e Coll (2002) têm discutido sobre a pertinência da compartimentalização dos saberes e a elaboração dos currículos escolares. O que deve ser compreendido é que o conhecimento não deve ser guardado em "gavetas", como se um tipo de saber não tivesse nenhuma relação com outro. O ensino da língua portuguesa, como língua materna, por exemplo, já não comporta a visão da suficiência da aprendizagem apenas da norma-padrão. É necessário que essa norma (no sentido de prescrição), em diálogo com outras "normas" (o que é considerado "normal" no uso corrente da língua, como a "norma" popular, a "norma" culta), seja ensinada não de forma acrítica, por meio de frases desconexas ou modelares que as gramáticas prescrevem, no que tange ao "certo" ou "errado", mas de forma crítica e, portanto, reflexiva, com base no ensino dos gêneros discursivos, que, segundo Bakhtin (1997), são tipos relativamente estáveis de enunciados elaborados segundo determinada esfera de troca social, que é a utilização da língua, mesmo sem termos consciência, em princípio, de que estamos utilizando um ou outro gênero. Os enunciados (orais e escritos), considerados unidades reais da comunicação discursiva, refletem o objeto de cada uma das esferas da atividade humana, de acordo não só com o seu conteúdo (tema) e estilo verbal (recursos lexicais e gramaticais da língua), mas também, principalmente, com a sua organização composicional. Todavia, convém lembrar que o ensino do gênero só nele mesmo também não é suficiente - o texto com o fim em si mesmo -, visto

Revista do GELNE, Natal/RN, Vol. 21 - Número 2: p. 70-85. 2019 
que as condições de produção e recepção dos discursos devem ser consideradas nas práticas pedagógicas de leitura e escrita.

Diante disso, a escola não será ainda reflexiva e relevante se, por exemplo, o ensino da língua, ainda que seja por meio do uso de gêneros discursivos na escola, estiver no contexto da disciplinarização dos currículos escolares, que insiste em atender a uma demanda de poder impeditiva da quebra de cristalizações paradigmáticas que pregam a intolerância e o preconceito em relação a determinados grupos. A disciplinarização estanque é reflexo da realidade do velho capitalismo (GEE, 2000), em que os indivíduos têm seus conhecimentos e habilidades divididos em peças e pedaços. Se levarmos essa leitura à realidade fabril, por exemplo, somente os "gerentes" e os "chefes" (a elite, nesse caso) são capazes de "juntar as peças" no processo de fabricação; caso contrário, o poder da elite seria posto em questão segundo a perspectiva dos trabalhadores da "linha de frente". É aí que predomina o perigo, na ideologia ${ }^{2}$ do antigo capitalismo, de tratar os indivíduos como seres sociais, em virtude dos riscos de questionamento contra a elite por meio da atuação de sindicatos e organizações coletivas. Essa postura procurava silenciar, o quanto possível, as vozes excluídas, nos campos social, cultural, histórico e político.

Contudo, novos paradigmas (GEE, 2000) têm surgido no mundo capitalista. Ao contrário dos do velho capitalismo, os conhecimentos dos trabalhadores da "linha de frente" são, agora, flexíveis e adaptáveis às novas circunstâncias, e isso é mais valioso do que o conhecimento específico estanque. A produção de trabalho é vista como um todo, não como uma soma de peças e pedaços. A pós-modernidade, com seu pensamento híbrido contra a sistematização de verdades absolutas (BAUMAN, 2000), tem elevado ao paroxismo, nesses novos paradigmas do novo capitalismo, a necessidade de rápida produção de produtos e serviços, com alta qualidade e menor preço, inserindo identidades específicas de consumidores, com um trabalho de design fortemente social, contextual e semiótico, manipulando, em muitos casos, os símbolos de identidade. A demanda do novo capitalismo tem inserido os excluídos no mundo do consumo, e isso tem, de certa forma, trazido felicidade a eles. Mas é bom deixar claro que essa inserção não é feita diretamente por causa do "bem-estar" dessas vozes, e sim pela finalidade do lucro - a inclusão, que é um grande benefício em prol daqueles que têm tido suas vozes silenciadas, não é motivada em si mesma, mas principalmente em prol da empresa que está preocupada com seus ganhos e que vê na inserção de tais vozes, pelo menos no discurso publicitário, uma forma de aumentar significativamente a venda de seus produtos.

Essas reflexões devem ser propedêuticas para o ensino de gêneros discursivos (o anúncio publicitário, gênero discutido neste artigo, não foge à regra). O que realmente deve interessar é uma abordagem de ensino que, segundo Rojo e Barbosa (2015), leve em conta os efeitos de sentido discursivos, as vozes, as apreciações de valor e os ecos ideológicos por meio dos quais o sujeito do discurso produz seus enunciados em diversos gêneros discursivos, viabilizando certas escolhas linguísticas em detrimento de outras. Por essa visão, penso que o ensino da língua requer mais que uma interdisciplinaridade, na qual as especializações do saber devem ser vistas como um todo e complexo inter-relacionado: o ensino da língua requer, tomando como base a acepção de Kumaravadivelu (apud MOITA LOIPES, 2006), uma visão indisciplinar, que envolve não só essa interrelação de conhecimentos (diálogo entre os das disciplinas Sociologia e Língua Portuguesa, por exemplo), como também a ideia de como determinado paradigma pode ser analisado e, possivelmente, desconstruído sob a ótica de diversas disciplinas. Entender, à luz daquela interrelação, como uma determinada propaganda exclui o homossexual na compra de perfumes no dia dos namorados - heteronormativamente os comerciais apresentam a figura do par homem $/ \mathrm{mulher} \mathrm{-}$ é um exemplo contundente de uma educação reflexiva e indisciplinar, no entendimento de que a

2 O conceito de ideologia será sumariamente trabalhado mais adiante. 
escola é um espaço aberto para a produção de um conhecimento plural, além de estar antenada às demandas do mundo globalizado (ALARCÃO, 2001).

Nesse sentido, a escola reflexiva transgride a unidimensionalidade curricular no momento em que promove a pluralidade metodológica em prol do discurso da tolerância (SACRISTÁN, 2002). A proposta de uma educação na cultura globalizada atende às demandas das sociedades hodiernas, que caminham para a validade e capacitação de generalizar ideias em prol da aceitação dos modos de vida de todos, modos esses considerados válidos (MOITA LOPES, 2006), de tal forma que se garanta a felicidade das pessoas. Trazer para a sala de aula essas discussões é entender a escola como uma instituição "glocalizada", segundo Kumaravadivelu (2006), no sentido de o global estar localizado e o local estar globalizado. Assim, a transmissão cultural é vista como um processo dialético, no qual as culturas em contato se (re)modelam, a ponto de ser impossível entender a dicotomia centro / periferia.

A globalização nos coloca diante de questões problematizadoras, tais como diversidade cultural versus homogeneização, preservação de valores universais versus aceitação das diferenças, dentre outras. Tais questões se voltam para processos contraditórios e plurais que ainda não foram suficientemente compreendidos e que são produzidos por grupos de identidades multifacetadas (o dos negros, dos rappers, dos homoafetivos etc.). Nesse âmbito, a cultura local é recriada para ser consumida no jogo das produções propriamente globais, permitindo-se entender a ideia de que a globalização não elimina o localismo, porque, paradoxalmente, a cultural global fortalece as identificações locais, já que o mundo, nessas últimas décadas, é pluralista, no discurso da competição que engendra novas interdependências globais com diversidades culturais evidentes. Tal discurso de competição, em diálogo com a agenda social vigente, incluirá o homoafetivo na mesma posição que o heteroafetivo ocupa. Não havia (e não há) impedimento legal de o homossexual comprar para o parceiro algum presente no Dia dos Namorados, mas agora isso é legitimado por meio do discurso, abrindo caminhos para legitimações de outras ordens, tais como os direitos civis do grupo dos homoafetivos. O global se volta para as necessidades locais; uma vez atendidas, cumpre os seus objetivos, imersos no novo capitalismo, que são a produtividade e o lucro (e isso é observado desde o antigo capitalismo), só que agora sob o discurso da legitimação de grupos até então excluídos. Estando o global em conjunção com o local, o local será modificado para acomodar o global e viceversa. O excluído passa a ser incluído pelo bem dele? Até um certo ponto, sim. No entanto, esse benefício está a serviço da capacidade de transformar homens e produtos em objetos de cálculo em prol do novo capitalismo, criando assim, segundo Melo e Novais (2009), uma eterna assimetria entre homens e empresas.

\section{Os novos estudos de letramento e a multissemioticidade}

Como já foi dito aqui, os novos estudos de letramento voltam-se para a chamada "virada cultural", cuja abordagem, no âmbito das práticas de letramento (produção e recepção), se reporta para a quebra de paradigmas que excluem certas leituras consideradas "desviantes", a favor daquelas consideradas "normais". A produção de um texto que abre a possibilidade de um homoafetivo participar de uma prática normalmente atribuída ao heterossexual, pela visão heteronormativa, seria considerada, na sua recepção, algo "fora do padrão". Na seção sobre a análise crítica dos discursos publicitários, essa questão será um pouco melhor trabalhada.

Pelos escritos de Gee (2000) e Street (2003), observa-se a defesa de um tipo de letramento que parte da visão de que a escrita não é autônoma, tendo em vista que está associada ao contexto sociocultural em que é produzida, às relações de poder e à ideologia na qual está sedimentada. Com 
isso, pode-se entender que não existe um letramento, e sim "letramentos", isto é, práticas sociais da escrita situadas em variados contextos.

Nessa perspectiva de letramento, questiona-se a tradicional dicotomia "fala' versus "escrita". O fato de existirem marcas do falado no escrito não é visto como algo negativo, e sim como uma característica de constituição heterogênea da escrita. Para os novos estudos de letramento, quebra-se o paradigma de a escrita e a fala serem tecnologias distintas, e isso também faz com que seja questionada até que ponto é pertinente, numa escola reflexiva, o ensino, em muitos casos, sem uma perspectiva crítica adequada, da norma padrão da língua. O modelo ideológico permite relacionar língua, letramento e sociedade segundo a visão de "língua real', que se reporta ao contexto social de práticas letradas. Assim, questiona-se não só o que é considerado "padrão", mas também os valores comportamentais transmitidos de geração em geração, tendo em vista que esses princípios também se corporificam por meio do uso linguístico (falado e/ou escrito), que pode incluir ou excluir pessoas.

É no sentido de se vislumbrar como positiva a relação dialética entre fala e escrita que ganha terreno a noção de multiletramentos, cuja perspectiva parte da consideração da multiplicidade cultural das populações cada vez mais inseridas no mundo digital e global. A emergência dos textos multissemióticos na pós-modernidade significa que devem ser reconhecidas as mudanças e alterações na linguagem da escrita, pois o texto pós-moderno não se limita à mera articulação entre frases e períodos. Os sons e as imagens se entrelaçam com o texto escrito para a construção de novos sentidos exigidos pela pós-modernidade, quebrando cristalizações e estigmas. Trata-se da comunicação multissemiótica, que sempre existiu, mas agora com maior ênfase, tendo em vista as atuais demandas globais.

A pós-modernidade é o campo fecundo para a hibridização de gêneros discursivos em prol da manifestação de poder e de ideologia nas relações sociais de uma determinada cultura. A fusão entre a imagem e o verbal nas práticas textuais multissemióticas promove a construção de novos sentidos, podendo quebrar alguns que venham a ser de caráter estigmatizador. Para Kress e van Leeuwen (1996) e Rojo (2012), a linguagem e as análises das práticas de letramento devem focalizar os textos multissemióticos, muito além da linguagem essencialmente baseada na escrita.

Quando se fala na produção de um signo em textos multissemióticos, desconstrói-se a noção de signo imotivado, defendida por Saussure (1995). A motivação do signo tem um caráter ideológico, o que vai de encontro à proposta estruturalista da linguagem, em que a cultura é vista como mero instrumento de comunicação. Para Bourdieu (2013) e Weber (2007), em diálogo com Gee (2000) e Street (2003), os sistemas simbólicos culturais não são meros instrumentos de comunicação, e sim instrumentos de legitimação do poder de uma determinada ordem vigente, e entendo, pelo contexto da presente pesquisa, que há uma necessária agenda de legitimação dos homoafetivos nos diversos campos do discurso, ainda que em meio a objetivos mesquinhos do novo capitalismo, já delineados anteriormente. $\mathrm{Na}$ visão da cultura como instrumento de poder, dentro dos novos estudos de letramento, o texto escrito já não é mais suficiente, tendo em vista que outros elementos semióticos concorrem para a produção e/ou quebra de sentidos.

\section{Análise Crítica do Discurso dos anúncios das marcas Leite de Rosas e $O$ Boticário}

Se contextualizarmos as questões dos multiletramentos à luz de Bourdieu (2013), veremos que há uma demanda pelas funções sociais que devem ser cumpridas pelos textos multissemióticos e que, por meio desses textos, são transformadas em funções políticas colaboradoras para a legitimação das diferenças. Por mais que as empresas promovam anúncios publicitários tendo como fim principal o aumento das vendas, ao delinearem, nos textos multissemióticos, para determinadas vozes 
excluídas determinados papéis temáticos, atribuídos heteronormativamente a vozes já legitimadas, os discursos preconceituosos serão paulatinamente desconstruídos.

Para fins de exemplificação, tomo como corpus dois anúncios publicitários.

O primeiro anúncio foi produzido pela marca "Leite de Rosas", que é um dos produtos mais tradicionais voltados para questões de beleza ou vistos simplesmente como artigos para o toucador. Trata-se do reconhecimento, em nível discursivo, de um casal homoafetivo como constituinte de uma família. A empresa lançou a "nova família de produtos Leite de Rosas", e, tendo em vista a ampliação dos produtos dessa marca, tal ideia contribuiu para a ampliação do termo "família" quebra-se, daí, o sentido heteronormativo de família ser constituída pelo binômio homem/mulher, a fim de que seja permitida aos homoafetivos a condição de constituírem família. $O$ anúncio foi lançado em outdoors e revistas diversas em 2015. A propaganda é reproduzida a seguir:

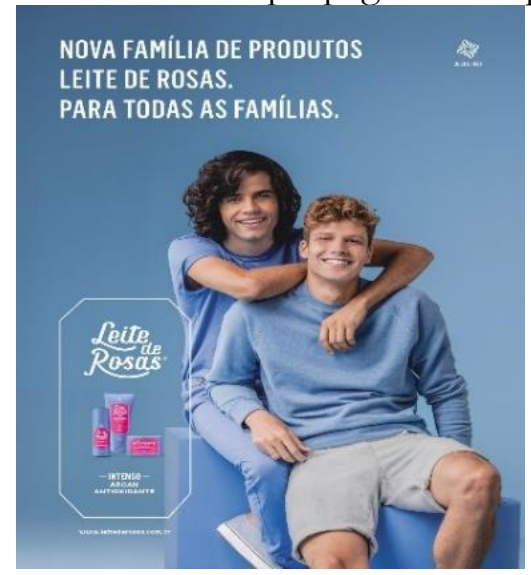

\section{Anúncio publicitário Leite de Rosas}

Fonte: www.universoaa.com.br/opiniao/a-familia-brasileira/ (acesso 21.05.2018).

O segundo anúncio foi exibido no horário nobre da Rede Globo de Televisão, na semana de comemoração do Dia dos Namorados. Produzido pela empresa O Boticário, também em 2015, o anúncio lança sete produtos da linha EGEO, mostrando diferentes tipos de casais, heterossexuais e homossexuais, trocando presentes. Assim como no anúncio de Leite de Rosas, houve também quebra e ampliação de sentido, só que agora no campo dos namorados: os homoafetivos também podem, além de constituir família, namorar, trocar presentes como qualquer heteroafetivo, e isso tem suscitado diversas críticas pelos heteronormativistas e despertado a curiosidade por parte de alguns ${ }^{3}$. Vejam as imagens, retiradas do comercial em voga:

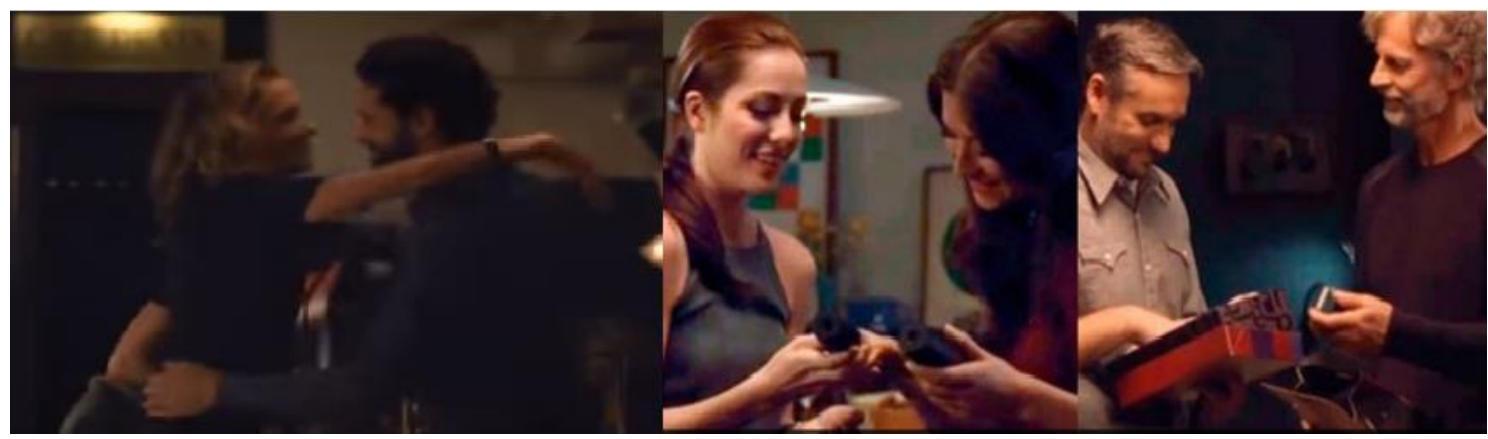

3 Vide http://www.visaonoticias.com/noticia/14866/propaganda-com-casal-gay-de-o-boticario-gera-guerra-de-opinioes (21.05.2018).

Revista do GELNE, Natal/RN, Vol. 21 - Número 2: p. 70-85. 2019 


\section{Anúncio publicitário $O$ Boticário \\ Fonte: https://youtu.be/QtMMDqBwJGU (acesso 30.06.18).}

Como esta pesquisa se circunscreve nos ditames da Linguística Aplicada (doravante LA) de cunho indisciplinar, cabem aqui algumas considerações.

Pennycook (apud MOITA LOPES, 2006) argumenta que ignorar as vozes reivindicadoras de múltiplas visões de mundo significa evitar uma LA mais responsável e militante. $\mathrm{Na}$ visão de Moita Lopes (2006), os novos modos de ver o mundo (pós-moderno e pós-colonial) são considerados transgressivos, porque, além de serem novas formas de politização, problematizam tópicos ainda não devidamente considerados pela Linguística Aplicada de cunho tradicional, tais como, por exemplo, identidade, sexualidade, ética, desejo, dentre outros. É bem provável que tal falta de consideração acima aventada seja motivada pelo fato de a Linguística ter ascendido do estruturalismo e do modernismo - a linguagem primariamente vista como um sistema e circunscrita nos paradigmas de pesquisa positivista, sem deixar de considerar a questão do signo imotivado proposto por Saussure (1995) -, não abraçando, no decorrer do tempo, as filosofias pós-estruturalistas e pós-modernistas, cuja visão se reporta às questões da linguagem que focalizam a desigualdade social e o poder, em diálogo com o que Bourdieu (2013) e Weber (2007) entendem a respeito de as condições materiaisideológicas influenciarem a produção de discursos, desconsiderando-se de tal maneira a ideia de os textos serem meros instrumentos possivelmente acríticos de comunicação. Nesse sentido, para se estabelecer a relação entre signo e ideologia, é necessário, em Volóchinov (2017), compreender que a ideologia, por ser social, construída em todas as esferas das interações, não pode derivar da consciência, segundo o que se entende pelo idealismo e pelo positivismo psicologista. A ideologia é vista como uma organização e expressão das relações histórico-materiais dos homens, cuja representação se dá na/pela linguagem.

A ideia de transgressão que corrobora com a "indisciplinaridade" da LA (MOITA LOPES, 2006) não tem a ver com desordem ou caos, mas sim com a necessidade de procurar, na acepção foucaultiana (2003), novos esquemas de politização que possam trazer à baila vozes até então ignoradas, quebrando os limites que as distanciam das benesses do exercício efetivo da cidadania. A importância de uma proposta transdisciplinar, na acepção de Rajagopalan (2003), desse tipo de linguística, é observada no que diz respeito aos diversos campos do saber que podem contribuir para uma determinada demanda social. A leitura das propagandas, segundo os novos estudos de letramento, não só elucida tal inclusão de cunho benéfico e necessário, como também põe em questão, de forma reveladora, o papel das empresas na busca desenfreada pelo lucro, de modo que elas não passem simplesmente, sob uma leitura "inocente" de mundo, como as "benfeitoras" da inclusão. Contudo, em meio a esse posicionamento crítico diante do verdadeiro papel das empresas e seus setores de marketing na produção de anúncios publicitários, insisto que não há como negar o fato de que as mudanças paradigmáticas, no reconhecimento do que seja, por exemplo, família, têm trazido benefícios de autoestima aos grupos homoafetivos, que merecem respeito e reconhecimento como os heteroafetivos. Com isso, a LA transdisciplinar, ou indisciplinar (MOITA LOPES, 2006), torna-se um projeto ético de renovação científica porque se volta para a defesa da responsabilidade e da solidariedade para com o outro na vida social, e a consequência disso é a promoção de novas formas de conhecimento, na acepção de que não se deve apenas descrever o mundo, mas também transformá-lo.

É nesse contexto que a Análise Crítica do Discurso (FAIRCLOUGH, 2001) se torna pertinente: ela não só descreve o mundo, mas também interfere nele. É por isso que a LA 
transdiciplinar tem, em seu caráter crítico $^{4}$, para o bem de todos, sem exceção, o papel militante, positivamente interventor, pois, nesse entendimento, os pesquisadores, de diversos campos das ciências humanas e sociais, contribuem para um tipo de LA que se torna híbrida, mestiça, em oposição à unidimensionalidade do fazer científico.

Para a empreitada de análise do discurso desses anúncios, escolheu-se, como já foi dito, a Análise Crítica do Discurso (doravante ACD), proposta por Norman Fairclough (2001), que entende a linguagem como aquela que constitui a sociedade, que por sua vez a regula. As práticas sociais, nessa visão, são naturalizadas, reforçadas e legitimadas por meio do discurso. A ACD é socialmente orientada em prol da mudança social, a partir da desmistificação de questões naturalizadas e não questionadas, no que se refere a desigualdades sociais em razão de questões religiosas, étnicas, classistas, linguísticas, de gênero e/ou orientação sexual, entre outros problemas hodiernos

Fairclough (2001) propõe um modelo de ACD chamado de teoria social do discurso. Trata-se de uma análise discursiva orientada, que pode levar em conta os elementos multissemióticos na interpretação de ideologias subjacentes aos textos, partindo-se do pressuposto de que a distribuição de poder, nas sociedades democráticas, se dá mais pela persuasão e consentimento do que pela coerção. Que verdades são veiculadas nos textos? Que paradigmas são quebrados em prol da promoção do discurso da efetiva democracia e do pleno exercício da cidadania? Como a ACD pode desnaturalizar o legitimado? Essas são algumas questões norteadoras da proposta da ACD.

Assim, Fairclough (2001) investiga criticamente o discurso por meio do modelo tridimensional de análise: as dimensões textual, discursiva e social, dimensões essas que estão em efetiva interação. A dimensão textual reporta-se ao nível linguístico do texto, no que tange às escolhas lexicais, gramaticais e estruturais do texto; a dimensão discursiva, aos processos de produção, distribuição e consumo dos textos; a dimensão social, às formas de hegemonia e ideologia presentes no texto em análise. Essas dimensões serão melhor elucidadas no momento da análise do corpus.

\subsection{O gênero discursivo anúncio publicitário}

Em primeiro lugar, convém ressaltar que tomo a acepção bakhtiniana como justificativa para o uso do qualificador "discursivo" no sintagma "gênero discursivo". Para Bakhtin (2016), o tema, o estilo e a construção composicional estão intrinsecamente ligados no enunciado e são determinados pela especificidade do contexto comunicacional. O texto é a materialização do discurso, que por sua vez determina a produção e a recepção dos textos, circunscritos em um determinado mundo discursivo (ADAM apud CHARAUDEAU \& MAINGUENEAU, 2008).

Por questões do exíguo espaço, este trabalho não pretende esgotar essas questões à luz da obra de Bakhtin. Por ora, sumariza-se que, como são inesgotáveis as possibilidades de atividade humana, cada atividade tem o seu campo circunscrito em um repertório de gêneros discursivos, sejam eles orais ou escritos. Aqui, entende-se que a atividade humana de propagar mercadorias ou serviços tem no anúncio publicitário o gênero discursivo ideal de realização.

\footnotetext{
${ }^{4}$ Isso não significa que a linha francesa de análise do discurso, por exemplo, não seja crítica. Para Maingueneau (2017), a fronteira entre a Análise Crítica do Discurso e a dita "não crítica" é questionável. O autor defende a ideia de que a fronteira entre as orientações de análise não passa de uma questão de realce, não sendo assim uma questão de natureza. O fato é que podem existir pesquisas que não se caracterizam por um viés militante, e isso seria a primeira diferença entre as abordagens, que são interdependentes no momento de se entender que o discurso é sempre marcado por questões com interesses específicos.
} 
Por meio do gênero discursivo propaganda ou anúncio publicitário ${ }^{5}$, a empresa procura despertar no interlocutor o desejo de adquirir determinado produto ou serviço. Incluem-se nessa intenção a publicidade de uma ideia ou da importância de se aderir a uma causa. Os panfletos, os folders, e, no caso desta pesquisa, os anúncios publicitários, todos de cunho persuasivo, valem-se de diferentes recursos multissemióticos capazes de obter a adesão do interlocutor àquilo que é promovido. Se a intenção persuasiva se associa à divulgação de algum item em larga escala, surge então, no campo comunicacional, a figura do anúncio publicitário, cujo suporte pode ser uma revista, um outdoor ou um comercial de rádio e/ou TV.

Os textos publicitários procuram responder a um desejo, muitas vezes inconsciente. Há quem diga que promessas são compradas, no lugar de produtos. Os dois anúncios do corpus retratam exatamente essa questão. É claro que as empresas querem vender de forma intensa, mas o resultado da propaganda vai muito além dessa expectativa, pois, ao inserir certas pessoas, o anúncio pode despertar nelas algum sonho a ser realizado de alguma forma, fazendo com que consumam os produtos anunciados (e os donos das empresas obtendo lucro com isso) e se realizem como dignas de um determinado reconhecimento perante a sociedade.

Segue-se então uma proposta de ACD dos anúncios aqui referidos, segundo a teoria social do discurso proposta de Fairclough (2001).

\subsection{A dimensão textual das propagandas}

Fairclough (2001) não fala claramente da multissemioticidade para a ACD. Todavia, é possível delinear alguma ideias a respeito das duas propagandas que formam o corpus desta pesquisa, já que esses anúncios, com todos os seus elementos verbais e não-verbais, são considerados textos, dotados de sentido e constituídos de recursos semióticos que não só propagam as mercadorias, mas também legitimam os homoafetivos como consumidores em potencial no contexto de consumo (no caso, a noção de família e do Dia dos Namorados nos anúncios Leite de Rosas e O Boticário, respectivamente) "legitimado" aos heteroafetivos.

Quanto à propaganda da marca Leite de Rosas, no que tange à dimensão textual, o predomínio da cor azul (cenário e roupas dos atores), referente à "linha azul" de perfume, remete-se à ideia de uma cor neutralizada (o "azul" normalmente é atribuído ao universo masculino) no momento em que se diz que o produto é unissex. Tal neutralização se confirma mais ainda quando há a quebra do conceito heteronormativo de família, normalmente voltado para a ideia de união entre o homem e a mulher, enquanto heteroafetivos. Quando a leitura do elemento verbal Nova família de produtos Leite de Rosas. Para todas as famílias é feita em conjunto com a imagem dos dois rapazes numa cena idílica (dois homens brancos e bem afeiçoados abraçados, o que, de certa forma, recupera a noção heteronormativa de um casal belo e feliz, própria da família dita como "normal" e única "legítima"), observa-se, a partir daquela quebra proposta, que há uma ampliação do conceito de família, que inclui a possibilidade de os homoafetivos a constituírem. Essa última acepção, embora não seja aceita pelo discurso heteronormativo ainda vigente ${ }^{6}$, é confirmada pela própria mentora do anúncio da

\footnotetext{
5 Para Droguell e Pompeu (2012), no Brasil não há uma distinção significativa entre "propaganda” e "publicidade”. Logo, esses termos podem ser usados de forma indiscriminada.

6 É comum observar, nos discursos produzidos por igrejas (neo)pentecostais, narrativas que acusam determinadas empresas de promoverem o homossexualismo nas sociedades. Como a escola reflexiva deve estar atenta não só às condições de produção dos discursos, mas também às de recepção desses discursos, observar, por exemplo, a postura homofóbica de um dos militantes que combate a promoção dos direitos dos homoafetivos, pelo menos em nível discursivo, o Pastor Silas Malafaia, é entender como é prejudicial para a sociedade dita democrática considerar como "desviante" a leitura de que os homoafetivos podem viver em sociedade como os heteroafetivos vivem, chegando a
} 
nova linha do produto Leite de Rosas, Julia Martins Ribas, gerente de marketing dessa marca. Para ela, o casal do anúncio é retratado como um dos tipos de famílias, pois a família pode ser constituída não só de homem, mulher e sua prole, mas também de pais solteiros ou de avós criando os netos, inclusive de homens e mulheres homossexuais. Mas é necessário ressaltar que não é consensual, pela visão heteronormativa, a ideia de homoafetivos constituírem família, e, em razão disso, não só o discurso publicitário, como também as telenovelas, têm motivado reflexões sobre a mudança de pensamento quanto ao lugar do homoafetivo na sociedade, que detém dos mesmos direitos, como, por exemplo, o de amar e de ser amado, que os heteroafetivos têm. Agora é inegável que esse jogo de marketing, em princípio a favor dos homoafetivos, pode aumentar os índices de vendas dos produtos, seja pela identificação com a ideia propagada ou simplesmente pelo desejo de ir contra ao que é vigente, bem como pode também motivar reações contrárias, como as de boicote por parte do consumidor heteronormativo. Mas é louvável que as empresas, mesmo com o risco de o objetivo de aumento de vendas ser fracassado, sejam protagonistas na mudança de discurso quanto aos direitos de todos, inclusive aos dos homoafetivos.

A propaganda de $O$ Boticário, na ocasião do Dia dos Namorados, mostra cenas em que diferentes tipos de casais, heterossexuais e homossexuais, trocam presentes. O comercial tem a duração de exatos 31 segundos. Nos 10 primeiros segundos, mostram-se cenas em que homens e mulheres se preparam (compram presentes, vestem a melhor roupa) para o encontro à noite do Dia dos Namorados. No $11^{\circ}$ segundo, uma mulher toca o interfone e, no segundo seguinte, um homem atende. Até aqui, parece um comercial como outro qualquer, no que se refere ao Dia dos Namorados, em se tratando de um encontro amoroso entre um homem e uma mulher. No $13^{\circ}$ segundo, após o atendimento do interfone pelo homem, a mulher entra pela porta do edifício, fazendo com que o telespectador pense que se trata de um encontro entre heteroafetivos, mesmo que esse pensamento seja inconsciente, já que é cristalizada a ideia, pelo menos na nossa sociedade, de ser comum, no Dia dos Namorados, um homem e uma mulher se encontrarem para um momento feliz de amor. No $14^{\circ}$ segundo, quando o homem abre a porta, há uma quebra de expectativa: não é a mulher que entra, como era de se esperar, e sim outro homem, ressignificando-se nessa cena o conceito sobre o Dia dos Namorados, na ideia de homoafetivos agora serem reconhecidos como pessoas que também comemoram esse dia e que, em diálogo com o anúncio anterior, podem constituir família, fazendo com que esse grupo, em consequência dessas possibilidades ressignificadas, seja incluído (não que assim já não o fosse, mas a legitimação dessa ideia é que se faz pertinente a partir do discurso, no caso, publicitário, quebrando-se o paradigma vigente em prol dos heterossexuais) no rol de consumidores considerados como alvo em potencial na compra de perfumes de O Boticário, principalmente no Dia dos Namorados. No entanto, não houve apagamento da noção de heteroafetivos como consumidores dos produtos dessa empresa e muito menos como aqueles que namoram, como se vê no $18^{\circ}$ segundo da cena. No $20^{\circ}$, inclui-se a noção de duas mulheres homoafetivas, já que o centro das atenções do mundo LGBT, normalmente, se dirige aos homens ${ }^{7}$. O anúncio finaliza com a cena da apresentação de sete modalidades do perfume EGEO. Curioso é que cada modalidade é verbalmente ressignificada como se fosse uma "tentação", por meio do texto oralizado No dia dos namorados, entregue-se às sete tentações de EGEO. O Boticário. Antecedida pelo modo injuntivo verbal "entregue-se a" e pelos determinantes "as" e "sete", a palavra "tentações", no plural, por referir-se aos sete tipos de perfume em anúncio - e o número

pregar o boicoite no que se refere à compra de produtos de empresas que são favoráveis à causa LGBT. A incoerência é que esses mesmos grupos heteronormativos divulgam o boicote em plataformas que, por sua vez, propagam ideias favoráveis aos homoafetivos.

${ }^{7}$ Essa visão tem sido questionada veemente pela militância do próprio universo LGBT. 
"sete" indicando a perfeição da ideia propagada, em que todos, sem exceção, agora podem desfrutar da vida feliz e plena -, pode ter duas leituras: a primeira, de forma mais inocente e mais estanque em relação às cenas apresentadas, pode referir-se à ideia de ser um pecado resistir à compra de um produto de alta qualidade; a segunda, obviamente mais ampla que a primeira, reporta-se à ideia de "tentação" ter sido provavelmente entextualizada ${ }^{8}$ do discurso religioso, que atribui como pecado o relacionamento sexual antes do casamento - em se tratando do Dia dos Namorados, pela visão heteronormativa dos religiosos, a relação sexual entre o homem e a mulher antes do matrimônio é pecado, e, a relação sexual entre homoafetivos é considerada abominação'. $\mathrm{Na}$ frase Aqui a vida é linda, escrita na cena dos dois últimos segundos do anúncio, o advérbio endofórico "aqui" sintetiza o que foi apresentado no anúncio numa forma de avaliação: as cenas representam as atitudes que valem a pena ser vividas, sem se preocupar com os ditames que os grupos tradicionais impõem. A vida apresentada no anúncio será uma realidade se o telespectador ceder à tentação ao comprar a linha de perfumes EGEO, e é aí que, nesse discurso de legitimação inclusiva de o homoafetivo ter o mesmo estilo de vida amorosa que os heterossexuais têm, as empresas têm um potencial de considerável faturamento.

\subsection{A dimensão discursiva das propagandas}

A dimensão do discurso como prática discursiva se remete à investigação de processos de produção, distribuição e consumo dos textos. Para este artigo, por questões de espaço, retomo apenas os conceitos de intertextualidade e interdiscursividade, segundo Fairclough (2001), em diálogo com outros estudiosos.

Para Bakhtin (1997, 2016), todo discurso é dialógico. Nesse sentido, observa-se o diálogo entre textos (intertextualidade) e o entre discursos (interdiscursividade). Esses dois fenômenos são muito parecidos, porém é necessário considerar a atuação de cada um. Pela intertextualidade, o interlocutor deve entender o que está escrito/dito e o que está apenas implícito em nível textual, ao passo que, pela interdiscursividade, o diálogo extrapola os limites do texto, porque, no interdiscurso, vários textos diferentes podem não dialogar no que tange à materialidade linguística, mas sim no que se refere à temática pertinente entre eles (FAIRCLOUGH, 2001). Para Orlandi (2001), o interdiscurso é a soma de tudo o que foi feito e já esquecido, mas que determina o nosso ato verbal. A intertextualidade sempre vai pressupor uma interdiscursividade, porém o contrário é falso (FAIRCLOUGH, 2001; FIORIN, 2006).

Pela intertextualidade, observa-se que os dois textos em análise obedecem aos cânones típicos do gênero "anúncio publicitário". Isso significa que os mentores dos anúncios não estão

\footnotetext{
${ }^{8}$ A noção de entextualização tem a ver com o trazer de um discurso para outro, de forma ressignificada. Trata-se de dois processos contíguos: a trajetória do texto no processo de descontextualização e o de ressignificação. Para Fabrício (2015), a entextualização é o processo de tornar extraível um discurso de um cenário para adquirir outras nuances semióticas em outro. No caso da propaganda de O Boticário, a segunda leitura a que me refiro faz entender que o anúncio entextualizou a ideia de tentação como algo positivo, como um ganho, tanto na compra do produto EGEO quanto na ideia de alguém viver feliz com quem ama, seja numa relação homo ou heteroafetiva.

9 A Bíblia Sagrada é o livro de referência para os católicos e protestantes. Há várias passagens bíblicas que comprovam a ideia de o relacionamento sexual antes do casamento ser considerado pecado e ser uma tentação a vontade de praticá-lo. Dentre as passagens, a mais contundente é 1 Coríntios 6:9-10, em que Paulo, na carta aos Coríntios, ensina como os cristãos devem se comportar quanto ao uso do corpo: "Vocês não sabem que os perversos não herdarão o Reino de Deus? Não se deixem enganar: nem imorais, nem idólatras, nem adúlteros, nem homossexuais passivos ou ativos, nem ladrões, nem avarentos, nem alcoólatras, nem caluniadores, nem trapaceiros herdarão o Reino de Deus" (A BÍBLIA, 2008).
} 
inventando tal gênero, mas seguindo o que foi estabelecido, no que se refere ao despertar no interlocutor o desejo de adquirir determinado produto ou serviço.

Quanto à interdiscursividade, entende-se que o discurso, de caráter abstrato, capta a forma de percepção ou visão de mundo em diferentes instituições (FOUCAULT, 2003). Nos anúncios, podemos ver dois textos diferentes, mas dialógicos quanto ao assunto sobre a família, só que numa proposta de quebra de conceitos tradicionais em prol da inclusão dos homoafetivos. Trabalhar essa temática em forma de anúncio publicitário é chamar atenção do público consumidor, homoafetivo ou não, para o produto que se alinha a uma ideologia polêmica, em se tratando de uma sociedade como o Brasil, que é bipolarmente conservadora e progressista. Incluir o homoafetivo como formador de famílias e como aquele que pode comprar presentes para o parceiro chama atenção da opinião pública, excita o discurso homofóbico dos heteronormativistas e, sob o aspecto do modismo, possibilita o aumento de venda, além de rotular as marcas anunciadas como vanguardistas, no que se refere ao reconhecimento e legitimação dos direitos do mundo LGBT.

\subsection{A dimensão social das propagandas}

Essa dimensão trata de questões ideológicas presentes no texto. Entende-se por ideologia como uma forma de concepção da realidade que beneficia certos grupos em detrimento de outros (MEURER, 2007). Reportando-se à noção de hegemonia, proposta por Gramsci (1968) - processo de legitimação das classes dominantes por meio da aceitação generalizada do modo de relação entre a economia, a sociedade e a visão de mundo que propõem - , as ideologias se apresentam como representação mental de uma relação real entre os homens e suas condições de existência, revestindo-se de condição imaginária, a fim de que se mantenham estáveis ou se transformem, segundo seus interesses particulares (LAKATOS, 1991).

Com base nessa breve visão sobre o que se entende por ideologia, é verdade que os dois anúncios em análise focalizam o direito dos homoafetivos numa acepção idílica de família e que têm como objetivo principal, nessa focalização, o despertar de uma polêmica para chamar a atenção do produto anunciado e, com isso, aumentar as vendas. Isso não pode ser desconsiderado, mesmo que seja pertinente a inclusão dos homoafetivos, que sofrem todos os dias com a discriminação do heteronormativismo, que começa a partir do momento em que se diz que as propagandas focalizadoras da homoafetividade devem ser banidas, e a compra de seus produtos boicotada ${ }^{10}$.

Quanto àquela visão idílica de família tradicional, isso poderia também ser quebrado por meio da inclusão da figura dos transgêneros e transexuais nas propagandas.

O papel dos novos estudos do letramento é observável no sentido de desconstruir o binômio de que uma leitura é "normal" e a outra, "desviante". A ACD vem ao encontro desses estudos, elucidando o real papel, no caso aqui da pesquisa, dos anúncios publicitários. Pela visão heteronormativa, o anúncio em que homoafetivos namoram e que trocam presentes no Dia dos Namorados seria um tipo de texto cuja leitura, ao aceitar o discurso de que essas pessoas também namoram e trocam presentes, seria "desviante"; o comercial que apresenta um homem e uma mulher como namorados, seria um texto de leitura "normal" ao aceitar que só os heterossexuais podem namorar e trocar presentes no Dia dos Namorados ou constituírem família. O momento é considerar que nenhuma leitura seja "desviante", tendo em vista que todos os comportamentos e suas leituras são "normais".

10 Vide https://noticias.gospelmais.com.br/malafaia-boicote-contra-o-boticario-comercial-gays-77083.html (acesso 01.07.2018). 
Se os anúncios fossem trabalhados numa aula de língua portuguesa, as reais intenções das marcas deveriam ser analisadas, mas sem negar a realidade da mudança de paradigmas que se faz presente quanto à aceitação do homoafetivo como ser humano em seu viver pleno.

\section{CONSIDERAÇÕES FINAIS}

Este artigo procurou delinear as propostas dos novos estudos de letramento referentes à desconstrução da ideia de que certos estados de coisas são considerados "normais", enquanto outros são "desviantes" ou "marginais", no que tange à produção e à recepção das práticas de letramento. Indo de encontro à postura behaviorista ou à perspectiva do conhecimento cognitivo, agregam-se aos estudos do letramento a visão da multissemioticidade do texto, corroborando-se, assim, para a cunhagem do termo multiletramentos. Os textos multissemióticos atendem às demandas das agendas da pós-modernidade, e uma delas é a percepção de que o homoafetivo deve ter os mesmos direitos que o heteroafetivo os tem.

Partindo-se do modelo tridimensional da ACD (nesta pesquisa, o anúncio publicitário como texto, prática discursiva e prática social), proposto por Fairclough (2001), observou-se que se motivaram reflexões sobre a legitimação do grupo dos homoafetivos, em nível discursivo, na figura de consumidor de produtos tradicionalmente destinado aos heterossexuais, mesmo que, em meio ao discurso de inclusão, seja observada a verdadeira intenção das empresas: incluir tais grupos para que de alguma forma se aumente o número de vendas.

Tendo como referência as contribuições dos novos estudos de letramento, em diálogo com a ACD, o uso de anúncios publicitários nas práticas pedagógicas de produção e leitura deve levar em conta as contribuições da ACD referentes às questões textuais, discursivas e sociais (FAIRCLOUGH, 2001), em prol da quebra de paradigmas. Isso só será possível se a instituição de ensino adotar uma postura crítica diante dos textos, em prol da relevância de uma educação reflexiva. Os anseios de inclusão dos homoafetivos na legitimação de serem consumidores, no campo do discurso, é também uma agenda de um mundo global de que a escola faz parte. Ela recebe as demandas da globalização e produz conhecimento para esse mundo (nesse caso, os alunos praticando letramentos de ideologias inclusivas, responsáveis e conscientes), e isso faz com que a escola seja considerada não como global, mas sim "glocal", reflexiva e pertinente para os tempos líquidos da pós-modernidade.

Ainda que esteja atrelado ao ideal de venda de produtos em prol do lucro, o novo capitalismo, cuja ideologia dialoga com a do pós-modernismo, vai promover, em meio à mesquinhez do ganho monetário a qualquer custo, a defesa de que todos têm acesso a determinados bens e serviços (discurso global), promovendo a inserção de vozes até então excluídas (discurso local) nesse caso, trata-se do bem de incluir, por exemplo, os homossexuais, que até então nunca tiveram vOz na legitimação do consumo de produtos, normalmente destinado aos heterossexuais. Todas essas discussões são válidas na análise de anúncio publicitários, que podem incluir tais vozes marginalizadas, e isso deve começar na educação de língua materna por meio de gêneros discursivos, caracterizando-se assim o papel reflexivo da escola.

\section{REFERÊNCIAS BIBLIOGRÁFICAS}

ALARCÃO, Isabel. Novas tendências nos paradigmas de investigação em educação. Escola reflexiva e nova racionalidade. Porto Alegre: Artmed, 2001.

APPLE, Michael W. Política cultural e educação. São Paulo: Cortez Editora, 2000.

BAKHTIN, Mikhail. Estética da criação verbal. São Paulo: Martins Fontes, 1997. 
. Os gêneros do discurso. Trad. Paulo Bezerra. São Paulo: Editora 34, 2016.

BAUMAN, Zygmunt. Modernidade líquida. Rio de Janeiro: Zahar Editora, 2000.

BÍBLIA. Tradução de João Ferreira Almeida. Rio de Janeiro: King Cross Publicações, 2008. 1110 p. Velho Testamento e Novo Testamento.

BOURDIEU, Pierre. A economia das trocas simbólicas. São Paulo: Perspectiva, 2013.

CHARAUDEAU, Patrick; MAINGUENEAU, Dominique. Dicionário de análise do discurso. São Paulo: Contexto, 2008, verbete "discurso".

COLL, César. Psicologia e currículo. São Paulo: Ática, 2002.

DROGUELL, Juan Guilhermo D. e POMPEU, Bruno. Dicionário técnico e crítico da comunicação publicitária. Conceitos fundamentais. São Paulo: Companhia dos Livros, 2012.

FABRÍCIO, B.F. 2015. Policing the bordeland in a digital lusophone territory: the pragmatics of entextualization. In. MOITA LOPES, L. P. (Org.). Global Portuguese. Linguistics ideologies in late modernity. Nova York: Routledge, 2015. Chapter 3. Kindle Edition.

FAIRCLOUGH, Norman. Discurso e mudança social. Brasília: Universidade de Brasília, 2001.

FIORIN, J. L. Interdiscursividade e intertextualidade. In: BRAIT, B. (Org.). Bakbtin: outros conceitoschave. São Paulo: Contexto, 2006.

FOUCAULT, Michel. A ordem do discurso. São Paulo: Loyola Editora, 2003.

GEE, J.P. The New Literacy Studies; from The New Litercay Studies; from "socially situated" to the work of the social. In.: Barton, D., Hamilton, M. and Ivanic, R. Situated Literacies: reading and writing in context. Routledge: London, 2000, chapter 1, Kindle Edition.

GRAMSCI, Antonio. Maquiavel, a Política e a História. Rio de Janeiro: Civilização Brasileira, 1968.

KATO, Mary. No mundo da escrita: uma perspectiva psicolinguística. São Paulo: Ática, 1986.

KRESS, G. e van LEEUWEN, T. Reading images. The grammar of visual design. Londres: Routledge, 1996.

. Multimodal texts and critical discourse analyses. In.: Proceedings of the First International Conference on Discourse Analysis. University of Lisbon, Portugal: Colibri, 1997.

KUMARAVADIVELU, B. A linguística aplicada na era da globalização. In.: MOITA LOPES, Luiz Paulo da. Por uma linguística aplicada indisciplinar. São Paulo: Parábola Editorial, 2006.

LAKATOS, Eva Maria. Sociologia geral. São Paulo: Atlas, 1991.

MAINGUENEAU, Dominique. Discurso e análise do discurso. São Paulo: Parábola, 2017.

Revista do GELNE, Natal/RN, Vol. 21 - Número 2: p. 70-85. 2019 
MELO, João Manuel Cardoso de; NOVAIS, Fernando. Capitalismo tardio e sociabilidade moderna. Campinas: Unesp, 2009.

MEURER, J.L. Gêneros textuais na análise crítica de Fairclough. In: MEURER, J.L; BONINI, A.; MOTTA-ROTH, D. (orgs.) Gêneros: teorias, métodos, debates. 2. ed. São Paulo: Parábola, 2007.

MOITA LOPES, Luiz Paulo da. Linguística Aplicada e vida contemporânea: problematização dos construtos que têm orientado a pesquisa. In.: Paulo: Parábola Editorial, 2006. (org.). Por uma linguística aplicada indisciplinar. São

ORLANDI, Eni. P. Análise de discurso. Princípios e procedimentos. Campinas: Pontes, 2001.

PENNYCOOK, Alastair. Uma linguística aplicada transgressiva. In.: (org.). Por uma linguística aplicada indisciplinar. São Paulo: Parábola Editorial, 2006.

RAJAGOPALAN, Kanavillil. Por uma linguística crítica: linguagem, identidade e questão da ética. São Paulo: Parábola, 2003.

ROJO, R. Pedagogia dos multiletramentos: diversidade cultural e de linguagens na escola. In: ROJO, R; MOURA, E (orgs). Multiletramentos na escola. São Paulo: Parábola Editorial, 2012, pp. 11-32.

Editorial, 2015.

; BARBOSA, J. P. Hipermodernidade, multiletramentos e gêneros discursivos. São Paulo: Parábola

SAUSSURE, Ferdinand. Curso de linguística geral. São Paulo: Cultrix, 1995.

STREET, B. What's "new" in New Literacy Studies? Critical approaches to literacy in theory and practice. Current Issues in Comparative Education. New York, vol. 5, n.2, p. 77-91, 2003.

SACRISTÁN, J. Gimeno. Educar e conviver na cultura global. Porto Alegre: Artmed, 2002.

SOARES, Magda. Letramento em três gêneros. Belo Horizonte: Autêntica, 1998.

TFOUNI, L.V. Letramento e alfabetização. São Paulo: Cortez, 2010.

VOLÓCHINOV, V. N. Marxismo e filosofia da linguagem: problemas fundamentais do método sociológica na ciência da linguagem. Trad. Sheila Grillo; Ekaterina Vólkova Américo. São Paulo: Editora 34, 2017.

WEBER, Max. A ética protestante e o "espírito" do capitalismo. São Paulo: Companhia das Letras, 2007.

Submetido em $02 / 09 / 2018$

Aceito em 14/02/2019

Publicado em 02/08/2019

Revista do GELNE, Natal/RN, Vol. 21 - Número 2: p. 70-85. 2019 